\title{
Abstracts from the literature
}

\section{Comparison of Bain and Magill circuits}

The Bain and Magill anaesthetic breathing systems were compared for spontaneous breathing during nitrous oxide in oxygen and halothane anaesthesia. A mean fresh gas flow (VF) of $150 \mathrm{ml} \cdot \mathrm{kg}^{-1} \cdot \mathrm{min}^{-1}$ (SD $: \pm 30$, range 106-250) was required with the Bain system to prevent rebreathing sufficient to cause respiratory stimulation; mean fresh gas flow/ expired minute volume ( $\left.\bar{V}_{F} / V_{E}\right)$ was $1.49(\mathrm{SD} \pm$ 0.32 , range $0.86-2,17$ ). Equivalent figures for the Magill attachment were a mean VF of $82 \mathrm{ml} \cdot \mathrm{kg}^{-1}$. $\mathrm{min}^{-l i}$ ( $S D \pm 19$, range $43-125$ ), while mean $\hat{\mathrm{VF}} / \dot{\mathrm{V}} \mathrm{E}$ was $0.76,(\mathrm{SD} \pm 0.19$, range $0.38-1.23, \mathrm{P}$ $<0.001$ ). The results attest the efficiency of the Magill attachment in terms of gas economics, and indicate the very high flows required to avoid respiratory stimulation in somc subjects when the Bain system is used. (Alexander JP. Clinical Comparison of the Bain and Magill anaesthetic systems during spontaneous respiration. $\mathrm{Br} J$ Anaesth 1982; $54: 1031-6$ )

Fever in patients with nasotracheal intubation Acute maxillary sinusitis developed in three critically ill patients who required mechanical ventilation. In all three, fever was the initial clinical manifestation. An obtunded state and an inability to speak delayed localization of the site of infection. Prolonged intubation, simultaneous use of nasal gastric tubes, poor healing, and large-diameter tracheal tubes likely contributed to the disease pathogenesis. Acute maxillary sinusitis may be the cause of unexplained fevers in patients with nasotracheal intubation. (Knodel AR, Beekman JF. Unexplained fevers in patients with nasotracheal intubation. JAMA 1982; $284 ; 868-70$ )

Bronchiolectasis following artificial ventilation Pulmonary barotrauma associated with artificial ventilation is recognised clinically as pneumothorax, pneumomediastinum, or subcutaneous emphysema. Eleven patients who died in the intensive care unit after artificial ventilation were found at necropsy to have pronounced bronchiolectasis, which was associated with a greatly increased physiological dead space during life. The condition was best predicted by the maximum level of positive end expiratory pressure and the duration of application of positive end expiratory pressure. The clinical course of the lesion in survivors is not known. Further detailed studies are needed, but it is suggested that high levels of positive end expiratory pressure should be used with caution. (Slavin G, Nunn JF, Crow J, Doré CJ. Bronchiolectasis - a complication of artificial ventilation. Br Med J $1982 ; 285: 931-4$ )

Nitroprusside in acute myocardial infarction

Sodium nitroprusside was administered by intravenous infusion to 163 randomly selected patients during the first 24 hours after hospitalization for typical acute myocardial infarction. Effects studied were mortality at one week, the incidence of cardiogenic shock, clinical signs of left ventricular failure, and peak levels of creatine kinase isoenzyme MB. A control group of 165 patients received standard medical treatment and infusion of five per cent glucose. The end point of the study was a significant reduction in mortality in the nitroprusside group; this was reached when five deaths had occurred in this group, as compared with 18 among the controls $(P<0.05)$. The incidence of cardiogenic shock, clinical signs of left-heart failure, and mean peak levels of creatine kinase isoenzyme MB were all reduced $(P<0.05)$. The results indicate that infusion of nitroprusside in the early phase of acute infarction limits complications, possibly by reducing infarct size. The drug was particularly effective in anterior-wall infarction. (Durrer $J D$, Lie KI, van Capelle FJL, Durrer D. Effect of sodium nitroprusside on mortality in acute myocardial infarction. $N$ Engl J Med. $1982 ; 306: 112 I-8$.) See also: Editorial. Passamani ER. Nitroprusside in myocardial infarction. N Engl J Med 1982; 306 : $1168-70$ 


\section{Prazosin and propranolol in preoperative management of pheochromocytoma}

Combined use of prazosin (a selective $\alpha_{1}$ antagonist) and propranolol was effective in preoperative management of three patients with norepinephrine (NE)-secreting pheochromocytoma (PHEO). On admission, all were symptomatic and had moderate to severe hypertension despite treatment with diuretics, propranolol, and sympatholytics. Optimal symptomatic and blood pressure (BP) control was achieved with 6 to $10 \mathrm{mg} /$ day of prazosin and 120 to $480 \mathrm{mg} /$ day of propranolol given every six $\mathrm{hr}$ in equally divided doses. With this therapy, BP and haematocrit were reduced to levels similar to those found in the postoperative period. The daily urinary excretion of catecholamines and their metabolites was not modified during therapy with prazosin and propranolol. There was a drop in supine systolic BP ( 40 to $64 \mathrm{mmHg}$ ) and diastolic BP (32 to $52 \mathrm{mmHg}$ ) in all patients one to two hr after the first dose of prazosin (1-mg tablet); in two subjects this was accompanied by a larger orthostatic fall (74 and $92 \mathrm{mmHg}$ systolic: 65 and $78 \mathrm{mmHg}$ diastolic BP). The high incidence of first-dose effect suggests that a single oral dose of $1 \mathrm{mg}$ of prazosin could aid in the diagnosis of PHEO. The effectiveness of prazosin in controlling the hypertension induced by NE-secreting PHEO suggests that, in man, pressure responses to augmented levels of $\mathrm{NE}$ are mediated solely through $\alpha_{1}$-receptors. (Cubeddu $L X$, Zarate NA, Rosales CB, Zschaeck DW. Prazosin and propranolol in preoperative management of pheochromocytoma. Clin Pharmacol Ther 1982; 32: $156-60)$

\section{Chronotropic and inotropic effects of local anaesthetic agents}

The direct chronotropic and inotropic effects of procaine, chloroprocaine, cocaine, lidocaine, mepivacaine, prilocaine, tetracaine, and bupivacaine were studied in an isolated guinea pig atrial preparation. All of the agents tended to produce a negative chronotropic and inotropic effect at high concentrations. Bupivacaine and tetracaine were most potent in terms of their negative chronotropic and inotropic effects, whereas procaine was least potent in terms of depression of atrial rate and contractility. The potency of the various agents with regard to their depressive cardiac effects is related to their potency as local anaesthetic agents. No stimulatory effect on atrial rate was observed with any of the agents. With regard to atrial contractility, chloroprocaine did show a biphasic effect, i.e., initial positive inotropic action followed subsequently by a negative inotropic effect. The concentration of the various local anaesthetics required to produce depression of cardiac rate and contractility which might be considered clinically significant occurred at concentrations which were higher than are usually seen during the normal use of these agents for regional anaesthesia. (Feldman HS, Covino BM, Sage DJ. Direct chronotropic and inotropic effects of local anesthetic agents in isolated guinea pig atria. Regional Anesth 1982; 7: 149-56)

\section{Effects of naloxone on foetal circulatory} responses to hypoxemia

The effects of opiate receptor antagonism on the foetal cardiovascular response to hypoxemia were examined using the radionuclide-labeled microsphere technique. Heart rate, blood pressure, and cardiac output were measured during baseline periods, during hypoxemia, and before and after infusion of either naloxone $\left(1 \mathrm{mg} \cdot \mathrm{kg}^{-1}\right)$ or an equivalent volume of 0.9 per cent saline solution. Seventeen foetal sheep were subjected to maternal hypoxemia by allowing the ewes to breathe 10 per cent oxygen ( 3 per cent carbon dioxide, 87 per cent nitrogen). The foetuses responded with bradycardia, increased blood pressure, and no significant change in combined ventricular output or placental blood flow. After naloxone, the bradycardia increased by 10 per cent, and both combined ventricular output and placental blood flow fell by 20 per cent. The foetal bradycardic response to naloxone was reversible with atropine. In foetuses with normal oxygenation of the blood (normoxemic), naloxone had no significant effect on heart rate and blood pressure. These data indicate that endogenous opiates (e.g., endorphin and enkephalin) are important in regulating the foetal circulation during hypoxia, and that the effects of opiate receptor antagonism may be mediated through the autonomic nervous system. (LaGamma EF, Itskovitz J, Rudolph AM. Effects of naloxone on fetal circula tory responses to hypoxemia. Amt J Obstet Gynecol $1982 ; 143: 933-40$ ) 